\title{
Increased Soluble PD-L1 Levels in the Plasma of Patients with Epithelial Ovarian Cancer Correlate with Plasma Levels of miR34a and miR200
}

\author{
MICHAEL I. KOUKOURAKIS ${ }^{1}$, EMMANUEL KONTOMANOLIS ${ }^{2}$, \\ MARIA SOTIROPOULOU ${ }^{3}$, ACHILLEAS MITRAKAS ${ }^{1}$, EVANGELIA DAFA ${ }^{2}$, \\ STAMATIA POULILIOU $^{1}$, EFTHIMIOS SIVRIDIS ${ }^{4}$ and ALEXANDRA GIATROMANOLAKI ${ }^{4}$ \\ Departments of ${ }^{1}$ Radiotherapy/Oncology, ${ }^{2}$ Obstetrics/Gynecology and ${ }^{4}$ Pathology, \\ Democritus University of Thrace, Alexandroupolis, Greece; \\ ${ }^{3}$ Department of Pathology, Alexandra Hospital, Athens, Greece
}

\begin{abstract}
Background: Recently, programmed cell death protein 1 (PD1) blocking and anti-programmed death-ligand 1 (PD-L1) agents were approved for the treatment of various human malignancies. Materials and Methods: Our study examined the expression of PD-L1 in neoplastic tissue (17 patients) and the plasma soluble (s)PD-L1 of 32 patients with ovarian carcinoma, in parallel with the levels of specific microRNAs (miRs), using immunohistochemistry, enzymelinked immunosorbent assay (ELISA) and real-time quantitative reverse transcription polymerase chain reaction (qRT-PCR), respectively. Results: PD-L1 levels were significantly higher in the plasma of patients with ovarian cancer compared to healthy women $(p=0.01)$. High miR200 levels were related to high $S P D-L 1$ levels $(p=0.03)$, whilst high miR34a levels were associated with low $S P D-L 1$ levels $(p=0.02)$. Immunohistochemical expression of $P D-L 1$ by cancer cells was not related to plasma miR levels, nor to the level of SPD-L1. Conclusion: As well as cancer cell expression of PD-L1, a high SPD-L1 level characterizes a subset of patients with ovarian cancer. The value of this latter feature as a biomarker for the administration of anti-PD-L1/PD1 therapy needs further evaluation. Micro-RNAs, such as miR34a and miR200, may have a role in the efficacy of immunotherapy.
\end{abstract}

Cytotoxic immune response mediated by T-cells is regulated by inhibitory and activation receptors. The immune

Correspondence to: Michael I. Koukourakis, MD, Department of Radiotherapy/Oncology, Democritus University of Thrace, Alexandroupolis 68100, Greece. Mobile: +30 6932480808, Fax: +30 2551030349, e-mail: targ@her.forthnet.gr

Key Words: Ovarian cancer, sPD-L1, miR200, miR34a, immunohistochemistry. checkpoint, programmed cell death protein 1 and antiprogrammed death-ligand 1 (PD1/PD-L1) pathway in T-cells is involved, among others, in the regulation of the activity of cytotoxic T-cells (1). The programmed death PD1 protein is a transmembrane receptor, expressed by T-cells, and B-cells, infiltrating the tumoral stroma. Tumor-infiltrating cytotoxic T-cells may have an important role in eliminating cancer cells. When PD1 binds to the B7 family of proteins, such as PD-L1 or PD-L2 ligands that are often present on the surface of dendritic cells or even tumor cells, the activation of effector T-cells, such as CD8+ cells, is repressed (2). Tumors develop an adaptive immune resistance through the overexpression of PD-L1 and-L2 ligands on cancer cell membranes, allowing cancer cells to counterattack, by binding T-cells on their PD1 receptors, and promoting T-cell apoptosis (3).

After a long period of frustrating clinical research, cancer immunotherapy trials focusing on the PD1/PD-L1 pathway have started to show encouraging results. The European Medicines Agency (EMA) has approved PD1-blocking agents (nivolumab and pembrolizumab) for the treatment of metastatic melanoma and other disease such as non-small cell lung and head-and-neck carcinomas $(4,5)$. Anti-PD-L1 agents, for example durvalumab, avelumab and atezolizumab, have been also approved by U.S Food and Drug Administration (FDA) for the treatment of recurrent or metastatic urothelial carcinomas, Meckel cell carcinoma, non-small cell lung carcinomas and squamous cell head-andneck carcinomas $(6,7)$. Anti-PD1/PD-L1 immunotherapy has revolutionized the treatment of metastatic cancer, and it is expected that the combination of such agents with radiotherapy may also open a new era for better local control for a variety of human carcinomas (8).

In the current study, we examined the expression of PDL1 in neoplastic tissue and of its soluble form in the plasma 
(sPD-L1) of patients with epithelial ovarian carcinoma. Moreover, the levels of specific microRNAs (miRs), postulated to be involved in anticancer immune response, in the plasma of these patients were assessed.

\section{Materials and Methods}

Patients and disease. This pilot study analyzed plasma collected from 32 patients with epithelial serous ovarian cancer (consecutive patients according to the date of admission), the day before surgery and before any therapeutic intervention. All patients were treated at the Alexandra Hospital, Athens, Greece. An additional cohort of plasma collected from eight healthy control women, undergoing routine blood tests, was also analyzed. Paraffin-embedded tumor tissue material was available for immunohistochemical analysis in 17 of these patients. The study was approved by the local Ethics and Research Committee (DS 6/16.03.2017). Informed consent was obtained from all individual participants included in the study. All procedures performed in the study were in accordance with the ethical standards of the institutional and the national research committee and with the 1964 Helsinki declaration and its later amendments.

Plasma isolation. Venous blood was collected in tubes using heparin as an anticoagulant. It was immediately overlaid on top of Histopaque (Histopaque ${ }^{\circledR}-1077$; Sigma-Aldrich, St Louis, MO, USA) and centrifuged at $1 \times 1,000 \times g$ for $30 \mathrm{~min}$ at room temperature. Plasma was collected and samples were stored in aliquots at $-20^{\circ} \mathrm{C}$ until analysis.

PD-L1 enzyme-linked immunosorbent assay. For detection of PD-L1, an ELISA kit was used (ab214565; Abcam, Cambridge, UK). The range of detection of PD-L1 protein reported for the kit was 21.87-1400 $\mathrm{pg} / \mathrm{ml}$. The lower limit of detection of the assay was $2.91 \mathrm{pg} / \mathrm{ml}$, which is 10 -fold lower than the lowest value obtained in the current study. Each sample was assessed in duplicate $(50 \mu \mathrm{l})$ in a 96-well ELISA dish. Antibody Cocktail $(50 \mu \mathrm{l})$ was added and plates were incubated for 1 $\mathrm{h}$ at room temperature. Three washes were performed with appropriate buffer, and $100 \mu \mathrm{l}$ of 3,3',5,5'-tetramethylbenzidine (TMB) substrate was added to each well. Following $10 \mathrm{~min}$ incubation in the dark, 100 $\mu l$ of stop solution was added. After $1 \mathrm{~min}$, the optical absorption was assessed at $450 \mathrm{~nm}$. The dish was sealed with a membrane of acetate cellulose to avoid evaporation throughout the procedure. A standard linear curve was created by assessing the light absorption in controls prepared with specific PD-L1 dilutions (17.8, 34.38, 68.75, 137.5, 275, $550,1100 \mathrm{pg} / \mathrm{ml})$. The concentration of PD-L1 in the test samples was calculated using the standard curve.

Immunohistochemistry. Immunohistochemistry for PD-L1 was performed on formalin-fixed paraffin-embedded tissue sections of $3 \mu \mathrm{m}$ placed on positively charged slides. Tissue blocks were retrieved from the archives of the Department of Pathology, Alexandra Hospital. The slides were then deparaffinized by xylene and rehydrated through graded ethanol solutions to water. The heatinduced epitope retrieval process was performed in a microwave oven. Slides were immersed in Dako EnVision FLEX (Santa Clara, CA, USA) Target Retrieval Solution ( $\mathrm{pH}$ 9.0) in a pre-heated container followed by incubation at $97^{\circ} \mathrm{C}$ for $5 \mathrm{~min}$ three times. The container was allowed to cool at room temperature for $20 \mathrm{~min}$ and then the slides were placed in Tris-buffered saline (TBS) solution containing Tween 20 (pH 7.6) for $10 \mathrm{~min}$.
For PD-L1 antibody tested in the current study, a polymer detection method with UltraVision Quanto Detection System (Cheshire, UK) was employed, due to increased sensitivity and detection simplicity. Non-specific background staining was blocked by pre-incubation with UltraVision Protein Block for $5 \mathrm{~min}$, followed by $6 \mathrm{~min}$ buffer washing twice. Slides were then incubated with rabbit monoclonal PD-L1 antibody (1:200; Abcam, Cambridge, UK) overnight at $4^{\circ} \mathrm{C}$. This antibody recognizes a specific extracellular domain of human PD-L1 (Phe19-Thr239). After overnight incubation, tissue sections were washed twice for $6 \mathrm{~min}$ in TBS and then UltraVision Hydrogen Peroxide Block was applied for $10 \mathrm{~min}$ in order to neutralize endogenous peroxide activity. The slides were again washed with buffer twice for $6 \mathrm{~min}$ and then incubated with Primary Antibody Amplifier Quanto (Cheshire, UK) for $10 \mathrm{~min}$. After washing with buffer twice for 6 min, HRP Polymer Quanto was applied and slides were incubated for another $10 \mathrm{~min}$. Subsequently, extensive washing with buffer was performed $(3 \times 6 \mathrm{~min})$ and tissue sections were incubated with DAB Quanto Chromogen (Cheshire, UK) for $6 \mathrm{~min}$. Finally, slides were washed with buffer, counterstained with hematoxylin OS (Vector, Peterborough, UK), dehydrated through graded ethanol solutions as well as xylene, and mounted in synthetic resin.

Slides were assessed at $\times 200$ magnification for all available optical fields and the percentage of cancer cells with membrane or cytoplasmic PD-L1 expression was recorded. PD-L1 staining was also assessed in tumor infiltrating inflammatory cells and macrophages. Cases were grouped into three categories according to the extent of PD-L1 expression by cancer cells: Negative expression, limited expression (expression in $20-60 \%$ of cells), and of extensive expression (expression in 70-95\% of cells).

miRNA detection. Isolation of miRNA from plasma was carried out using a commercially available kit (Macherey-NageI, Duren, Germany) according to the manufacturer's instructions. Isolated miRNA was reverse transcribed via MiR-miRNA First Strand Synthesis kit (Clonetech Laboratories Inc., Mountain View, CA, USA) using mRQ buffer $(2 \times)$ and mRQ enzyme ( 1 h incubation at $37^{\circ} \mathrm{C}$, in an RNAase-free $0.2 \mathrm{ml}$ tube). The cDNA was diluted $1: 10$ and analyzed in a Roche Light Cycler 480II (Mannheim. Germany) using KAPA SYBR FAST qPCR kit Optimized for Light Cycler 480 (KAPA BIOSYSTEMS, Wilmington, MA, USA). For the real-time quantitative reverse transcription polymerase chain reaction, the primers used for amplification were as follows: $h s a-m i R-15 a-5 p$ (forward): 5-GCCGC TAGCAGCACATAATCCTT-3; $h s a-m i R-34 a$ $5 p$ (forward): 5-GCCGC TGGCAGTGTCTTAGC-3; $h s a-m i R-200 a-$ $3 p$ (forward): 5-GCCGC TAACACTGTCGGTAAC-3; $h s a-m i R$ 197-3p (forward): 5-GCCGC TTCACCACCTTCTCC-3; U6 snRNA was used as housekeeping control. The above primers were used together with the universal reverse primer from the MiRmiRNA First Strand Synthesis kit (Clonetech Laboratories Inc. Mountain View, CA, USA). Relative $m i R-15 a, m i R 34 a, m i R-200 a$ and $m i R-197$ levels were calculated using the comparative threshold cycle $(\mathrm{Ct})$ method. The levels of these miRNAs were compared between samples before and after surgical tumor removal.

Statistical analysis. Statistical analysis was performed using the GraphPad Prism 5.0 (GraphPad Software Inc., La Jolla, CA, USA). The unpaired two-tailed $t$-test or the one-way ANOVA test was used to compare groups with continuous data, as appropriate. A $p$-value of less than 0.05 was used for significance. 
A
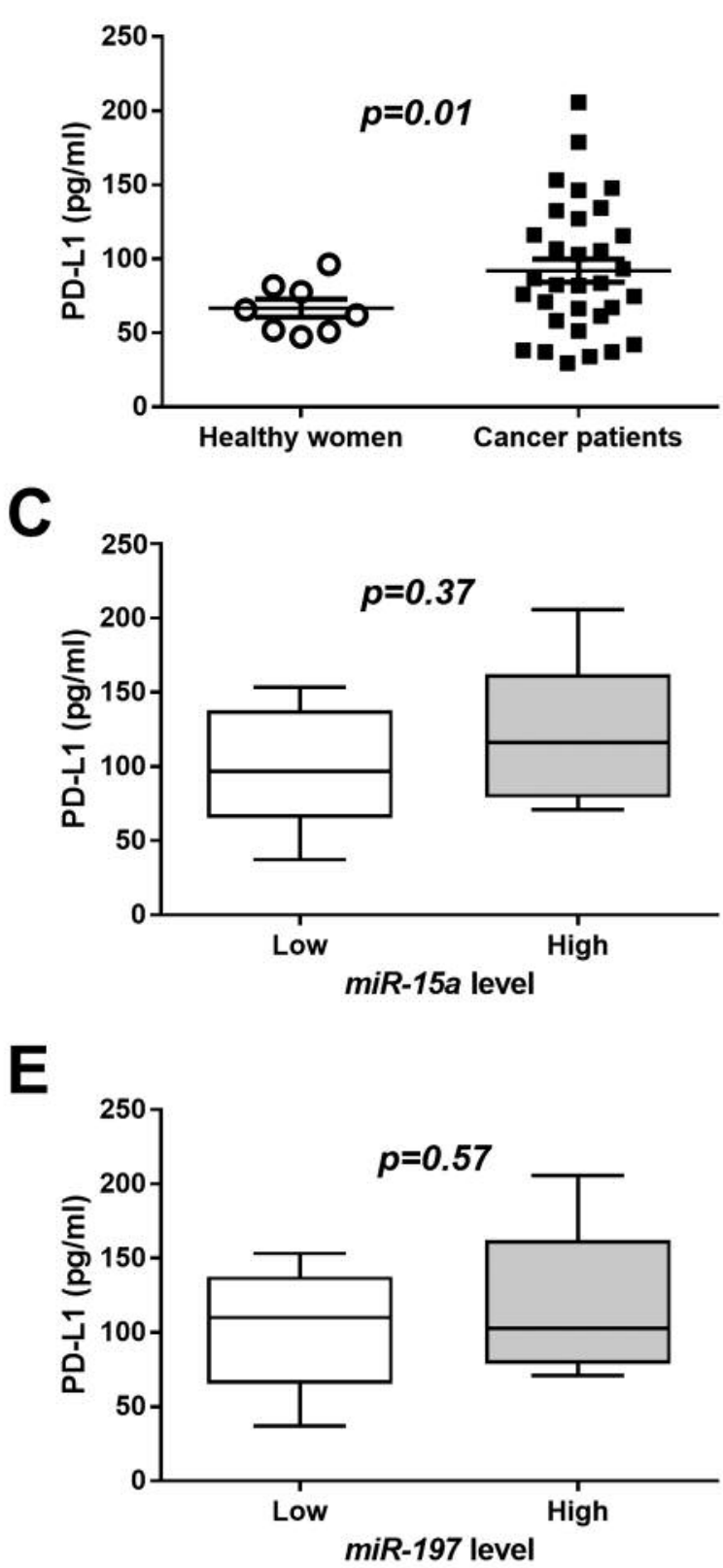

B

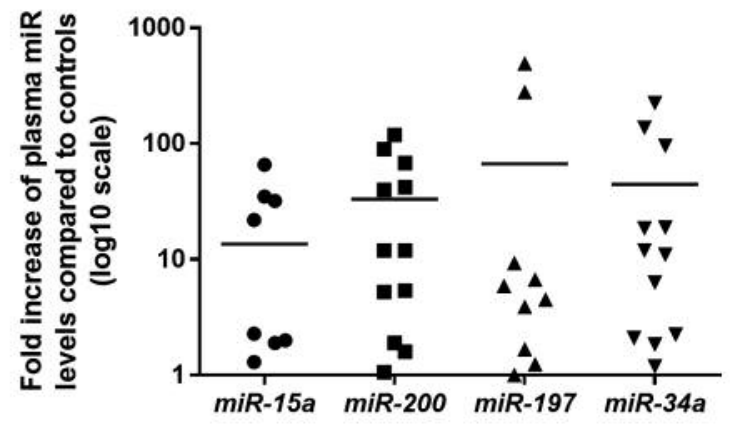

D

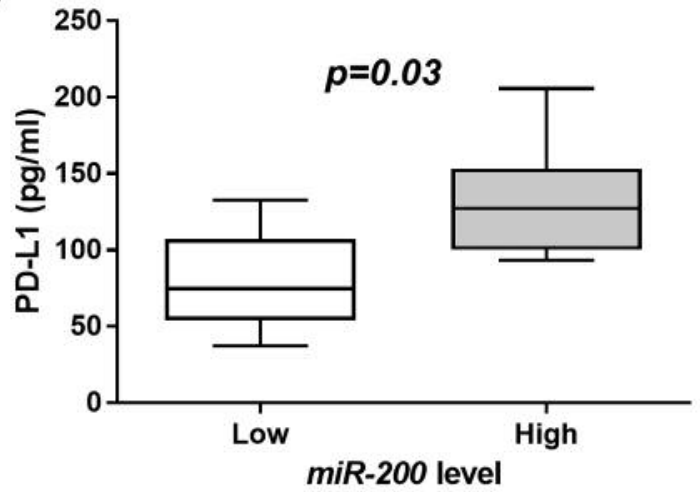

F

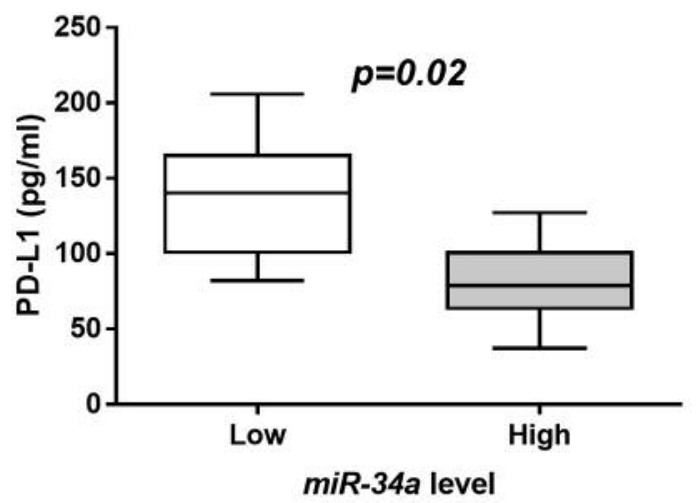

Figure 1. A: Scatter plot analysis of soluble programmed death-ligand 1 (sPD-L1) levels in plasma from healthy individuals and patients with ovarian cancer. Significantly higher levels were recorded in patients with cancer. B: Scatter plot analysis of the fold increase of miRNA levels in plasma from patients with ovarian cancer compared to healthy controls. C-F: Box and whiskers graphs of the sPD-L1 expression in the plasma of patients with cancer according to miRNA expression status (low vs. high). Boxes show the 25-75 percentiles, lines represent the median value, while bars show the range of values.

\section{Results}

sPD-L1 levels in plasma. PD-L1 levels were significantly higher in the plasma of patients with ovarian cancer compared to healthy women [median (range) $=83(29-205)$ vs. 63 (47-98) pg/ml; $p=0.01$; Figure $1 \mathrm{~A}]$. Using the upper normal value recorded in healthy control individuals $(98 \mathrm{pg} / \mathrm{ml})$ as a cut-off point, overexpression of sPD-L1 was observed in $14 / 32(43.7 \%)$ patients with ovarian cancer. 

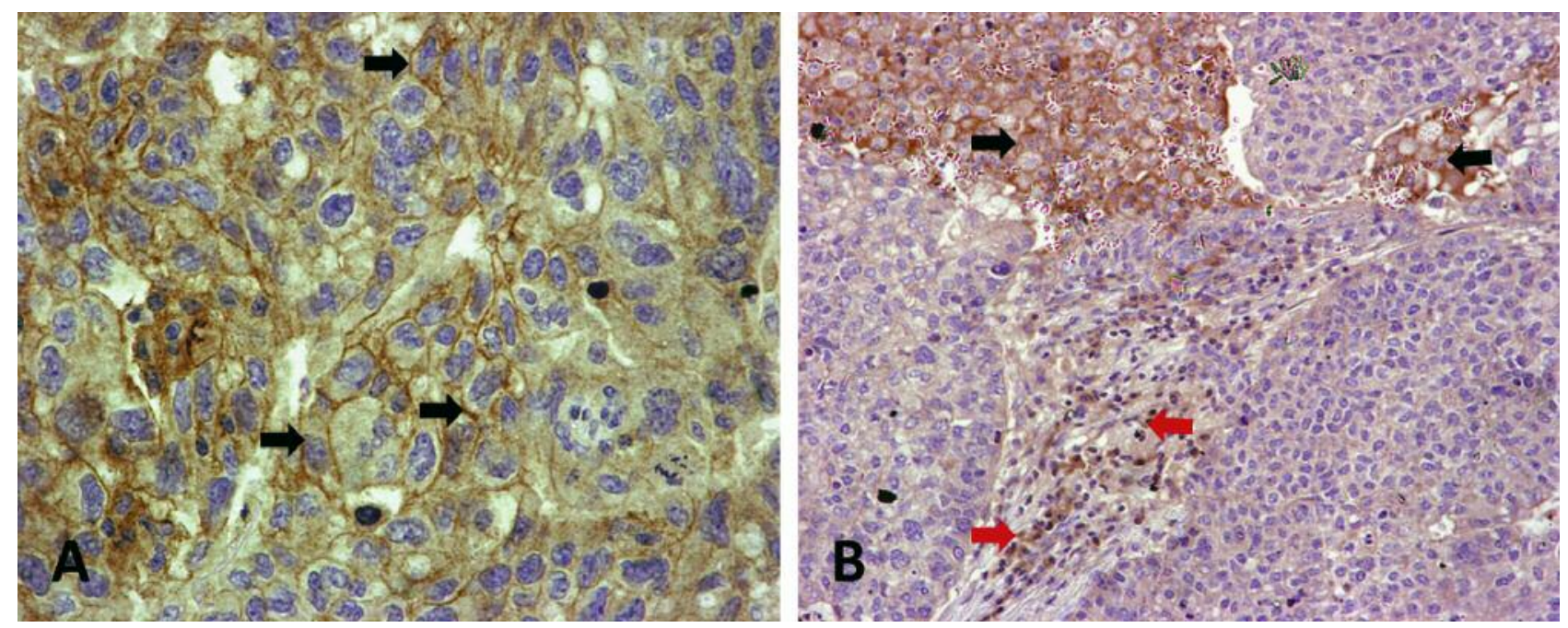

Figure 2. A: A serous ovarian carcinoma showing programmed death-ligand 1 (PD-L1) expressed in the membrane of cancer cells (black arrows). B: A case of serous ovarian cancer in which the tumor stroma is infiltrated by PD-L1-expressing lymphocytes (red arrows) and PD-L1-expressing foamy macrophages (black arrows).

miR levels in plasma. Four miRs were assessed in the plasma of patients, namely $m i R 15 a, m i R 200, m i R 197, m i R 34 a$, all of them being previously postulated to be involved in regulation of immune response (see Discussion). Increase of miR levels by several fold in patients with ovarian carcinoma compared to healthy individuals was noted (Figure 1B). Median (range) fold increases for miR15a, miR200, miR197 and miR34a were 1.9 (1-66), 12 (1-119), $4.2(1-493)$ and 2.1 (1.2-225), respectively.

Using the median values, cases were grouped into two categories, with low vs. high plasma miR level. Analysis of sPD-L1 levels according to these groups is shown in Figure 1CF. Patients with a high $m i R 200$ level had a significantly higher sPD-L1 level $(p=0.03)$ than those with a low miR200 level. On the contrary, patients with a high miR34a level had a lower sPD-L1 level $(p=0.02)$ than those with a low miR34a level.

PD-L1 expression in cancer cells. Using immunohistochemistry, we assessed the expression of PD-L1 in cancer cells in 17 available tissue specimens from patients that underwent surgery before chemotherapy. In 6/17, there was no PD-L1 expression in cancer cells. In the remaining 11 patients, there was membranous and cytoplasmic reactivity in $20-95 \%$ of the cancer cell population (median $=60 \%$ ). Typical expression is shown in Figure 2A. Cases were grouped into three categories: Negative expression: 6/17; limited expression (expression in 20-60\% of cells): $7 / 17$ cases; and of extensive expression (expression in $70-95 \%$ of cells): $4 / 17$ cases. There was no association of the plasma PD-L1 level with the immunohistochemical pattern (data not shown). No association of the plasma miR level with the immunohistochemical expression of PD-L1 was found (data not shown).

PD-L1 expression in the tumor stroma. PD-L1 was also expressed in the stroma of tumors, by tumor-infiltrating lymphocytes or foamy macrophages, even in the context of lack of expression in cancer cells (Figure 2B). Out of 17 cases, $10(58.8 \%)$ showed this pattern of expression, the remaining being negative in the stroma. StromaI PD-L1 expression was not related to cancer cell expression. In fact, $4 / 6$ cases with lack of PD-L1 expression in cancer cells expressed PD-L1 in stroma-infiltrating immune cells. There was no association of stromaI PD-L1 expression with miRNA expression in the plasma (data not shown).

\section{Discussion}

Epithelial ovarian cancer (EOC) is considered the first cause of death among patients with gynecological neoplasms, despite the fact that its incidence is 10 -fold lower than that of breast cancer and 5-fold lower than that of cervical cancer (9). Although high response rates are obtained after chemotherapy with various compounds, including platinum, taxanes, doxorubicin, or camptothecins, most patients experience recurrence and die from their disease (10). Antiangiogenic agents have shown a marginal benefit (11).

Recently, immunotherapy blocking the PD1/PD-L1 pathway has shown important efficacy in several human carcinoma types and this has encouraged clinical experimentation in patients with EOC. Although large 
studies are not available, as yet, a $15 \%$ response rate has been documented with nivolumab in patients with cisplatinresistant ovarian cancer (12). The objective response rate to pembrolizumab, avelumab or durvalumab is similarly low (13-15). A major problem in the establishment of antiPD1/PD-L1 therapies, is the identification of reliable biomarkers allowing the identification of subgroups of patients with disease that is sensitive to immunotherapy. The expression of PD-L1 on tumor cells is the main marker used for the time being, but its role is not consistent, probably due heterogeneous techniques in the identification and assessment of PD-L1 expression. Moreover, the fact that tumor-infiltrating inflammatory cells, such as macrophages or T-cells, in the tumor microenvironment express PD-L1 shows that PD1 blockage on cytotoxic lymphocytes may be regulated by pathways independently of PD-L1 expression by cancer cells $(16,17)$.

Several studies showed that PD-L1 is expressed by ovarian cancer. Hamanishi et al. reported that high cancer cell expression of PD-L1 was associated with reduced tumor infiltration by T-cells and poor survival (18). Aust et al. found that PD-L1 expression increased in recurrent ovarian carcinomas (19). Moreover, Darb-Esfahani et al. found that $76 \%$ of ovarian carcinomas expressed PD-L1 in cancer cells, although PD-L1 was also expressed by tumor-infiltrating lymphocytes (20). On the contrary, Webb et al. reported that PD-L1 in EOC is mainly expressed by tumor-infiltrating macrophages and is associated with a better survival (21). Similarly, Gottlieb et al. found a low overall expression of PD-L1 in serous ovarian cancer cells $(8 \%)$, but a frequent expression by tumor-associated macrophages ( $74 \%$ of cases) (22). In our study, using an antibody recognizing the extracellular domain of the protein, PD-L1 was expressed in $64.8 \%$ of cases. The above contradictory data are probably the result of the different antibodies and assessment methods applied by the researchers, which stress the importance of thorough and comparative investigation of the expression patterns obtained by different PDL1 antibodies recognizing different extracellular or intracellular epitopes of the protein. We also confirmed that PD-L1 is extensively expressed by tumor stroma-infiltrating T-cells and foamy macrophages in $58.8 \%$ of tumor samples examined.

We further assessed the expression of sPD-L1 in the plasma of patients with EOC. Using a cohort of healthy women, we identified a cut-off point for normal PD-L1 levels, which was estimated at $98 \mathrm{pg} / \mathrm{ml}$. Overexpression of sPD-L1 in the plasma of patients with ovarian cancer was found to be a frequent event, occurring in $43.7 \%$ of patients analyzed. Comparative analysis with cancer cell expression showed that SPD-L1 levels in the plasma were not dependent on the expression levels in cancer cells. This shows that immunosuppressive circulating SPD-L1 protein may have additional sources, as indeed suggested by several studies, including the current, showing overexpression of PD-L1 by tumor-associated macrophages and lymphocytes (20-22). In a recent study Chatterjee $e t$ al. also found overexpression of sPD-L1 in the plasma of patients with ovarian cancer and benign ovarian diseases (23). Moreover, high PD-L1 expression by circulating lymphocytes was directly linked with poor prognosis of patients with cancer. Whether sPDL1 is a biomarker of immunosuppression demands thorough investigation, but the source of sPD-L1 may be the immune system itself. Zhou et al. identified splice variants of the PDL1 protein that lack the transmembrane domain, these are released in extracellular space, and these variants sustain their immune suppressive activity (24). Indeed, high sPD-L1 levels have been associated with ominous prognosis in renal cancer and hematological malignancies $(25,26)$.

The molecular mechanisms related to PD-L1 expression in cells is under intense investigation. Cytokines released by immune cells or cancer cells, oncogene activation or even exposure to cytotoxic agents have been implicated in the upregulation of PD-L1 (27-30). Here, we provide in vivo evidence that miRNAs are involved in the regulation of PD-L1 expression. By examining the levels of four miRNAs, namely miR $15 a$, miR200, miR 197 and $m i R 34 a$, previously postulated to be involved in immune response (31-36), a several-fold increase of their levels were noted in subgroups of patients with ovarian cancer compared to healthy individuals. Of interest, patients with high miR34a levels exhibited low plasma sPD-L1 levels. These findings are in accordance with previously in vitro published studies. $m i R 34 a$ has been found to directly bind to the PD-L1 3' untranslated region and directly down-regulate the expression of PD-L1 in the cell membrane $(33,34)$. Previous in vitro studies also suggest that $m i R 200$ down-regulates the expression of PD-L1 $(35,36)$. However, our in vivo data showed a significant association of high plasma miR200 levels with high sPD-L1 protein expression.

In the current study, we provide evidence that apart from cancer cells, infiltrating immune cells and eventually circulating immune cells expressing PD-L1 immune suppressing ligand characterize a subset of patients with ovarian cancer. This should be taken into account in the quest to identify appropriate biomarkers for the administration of therapeutic monoclonal antibodies targeting PD-L1/PD1. Moreover, miR34a was revealed herein as a possible putative target for further therapeutic developments.

\section{Ethical Statements}

All patients provided their written informed consent for sample collection and further analysis was approved by the local Ethics and Research Committee. The study was performed in accordance with the ethical standards as laid down in the 1964 Declaration of Helsinki and its later amendments or comparable ethical standards. 


\section{Conflicts of Interest}

The Authors declare that they have no conflict of interest in regard to this study.

\section{Acknowledgements}

The study was financially supported by the Tumour and Angiogenesis Research Group.

\section{References}

1 Pardoll DM: The blockade of immune checkpoints in cancer immunotherapy. Nat Rev Cancer 12: 252-264, 2012.

2 Freeman GJ, Long AJ, Iwai Y, Bourque K, Chernova T, Nishimura H, Fitz LJ, Malenkovich N, Okazaki T, Byrne MC, Horton HF, Fouser L, Carter L, Ling V, Bowman MR, Carreno BM, Collins M, Wood CR and Honjo T: Engagement of the PD1 immunoinhibitory receptor by a novel B7 family member leads to negative regulation of lymphocyte activation. J Exp Med 192: 1027-1034, 2000.

3 Taube JM, Anders RA, Young GD, Xu H, Sharma R, McMiller TL, Chen S, Klein AP, Pardoll DM, Topalian SL and Chen L: Colocalization of inflammatory response with B7-h1 expression in human melanocytic lesions supports an adaptive resistance mechanism of immune escape. Sci Trans1 Med 4: 127ra37, 2012.

4 Robert C, Long GV, Brady B, Dutriaux C, Maio M, Mortier L, Hassel JC, Rutkowski P, McNeil C, Kalinka-Warzocha E and Savage KJ, Hernberg MM, Lebbé C, Charles J, Mihalcioiu C, Chiarion-Sileni V and Mauch C, Cognetti F, Arance A, Schmidt $\mathrm{H}$, Schadendorf D, Gogas H, Lundgren-Eriksson L and Horak C, Sharkey B, Waxman IM, Atkinson V and Ascierto PA: Nivolumab in previously untreated melanoma without $B R A F$ mutation. N Engl J Med 372: 320-330, 2016.

5 Morgensztern D and Herbst RS: Nivolumab and pembrolizumab for non-small cell lung cancer. Clin Cancer Res 22: 3713-3717, 2016.

6 Farina MS, Lundgren KT and Bellmunt J: Immunotherapy in urothelial cancer: Recent results and future perspectives. Drugs 77: 1077-1089, 2017.

7 Ferris RL, Blumenschein G Jr, Fayette J, Guigay J, Colevas AD, Licitra L, Harrington K, Kasper S, Vokes EE, Even C, Worden F, Saba NF, Iglesias Docampo LC, Haddad R, Rordorf T, Kiyota N, Tahara M, Monga M, Lynch M, Geese WJ, Kopit J, Shaw JW and Gillison ML: Nivolumab for recurrent squamous-cell carcinoma of the head and neck. N Engl J Med 375: 1856-1867, 2017.

8 Dovedi SJ, Cheadle EJ, Popple AL, Poon E, Morrow M, Stewart R, Yusko EC, Sanders CM, Vignali M, Emerson RO, Robins HS, Wilkinson RW, Honeychurch $\mathbf{J}$ and Illidge TM: Fractionated radiation therapy stimulates antitumor immunity mediated by both resident and infiltrating polyclonal T-cell populations when combined with PD-1 blockade. Clin Cancer Res 23: 5514-5526, 2017.

9 Siegel RL, Miller KD and Jemal A: Cancer statistics, 2017. CA Cancer J Clin 67: 7-30, 2017.

10 Bookman MA: Optimal primary therapy of ovarian cancer. Ann Oncol 27(Suppl 1): i58-i62, 2016.
11 Rossi L, Verrico M, Zaccarelli E, Papa A, Colonna M, Strudel M, Vici P, Bianco V and Tomao F: Bevacizumab in ovarian cancer: A critical review of phase III studies. Oncotarget 8 : 12389-12405, 2017.

12 Hamanishi J, Mandai M, Ikeda T, Minami M, Kawaguchi A, Murayama T, Kanai M, Mori Y, Matsumoto S, Chikuma S, Matsumura N, Abiko K, Baba T, Yamaguchi K, Ueda A, Hosoe Y, Morita S, Yokode M, Shimizu A, Honjo T and Konishi I: Safety and antitumor activity of anti-PD-1 antibody, nivolumab, in patients with platinum-resistant ovarian cancer. J Clin Oncol 33: 4015-22, 2015.

13 Varga A, Piha-Paul SA, Ott PA, Mehnert JM, Berton-Rigaud D and Johnson EA, Cheng JD, Yuan S, Rubin EH and Matei DE: Antitumor activity and safety of pembrolizumab in patients (pts) with PD-L1 positive advanced ovarian cancer: Interim results from a phase Ib study. J Clin Oncol 33(suppl): abstr 5510, 2015.

14 Disis ML, Patel MR, Pant S, Hamilton EP, Lockhart AC, Kelly K, Thaddeus-Beck J and Gordon M, Weiss GJ, Ejadi S, Taylor MH, Chin K, Cuillerot JM, Von Heydebreck A and Gulley JL: Avelumab (MSB0010718C; anti-PD-L1) in patients with recurrent/refractory ovarian cancer from the JAVELIN solid tumor phase Ib trial: Safety and clinical activity. J Clin Oncol 34(suppl): abstr5533, 2016.

15 Lee J, Zimmer AD, Lipkowitz S, Annunziata CM, Ho TW, Chiou VL, Minasian LM, Houston ND, Ekwede I and Kohn EC: Phase I study of the PD-L1 inhibitor, durvalumab (MEDI4736; D) in combination with a PARP inhibitor, olaparib (O) or a VEGFR inhibitor, cediranib (C) in women's cancers (NCT02484404). J Clin Oncol 34(suppl): abstr 3015, 2016.

16 Prima V, Kaliberova LN, Kaliberov S, Curiel DT and Kusmartsev S: COX2/mPGES1/PGE2 pathway regulates PD-L1 expression in tumor-associated macrophages and myeloid-derived suppressor cells. Proc Natl Acad Sci USA 114: 1117-1122, 2017.

17 Qu QX, Huang Q, Shen Y, Zhu YB and Zhang XG: The increase of circulating PD-L1-expressing CD68(+) macrophage in ovarian cancer. Tumour Biol 37: 5031-5037, 2016.

18 Hamanishi J, Mandai M, Iwasaki M, Okazaki T, Tanaka Y, Yamaguchi K, Higuchi T, Yagi H, Takakura K, Minato N, Honjo T and Fuiji S: Programmed cell death 1 ligand 1 and tumorinfiltrating CD8+ T-lymphocytes are prognostic factors of human ovarian cancer. Proc Natl Acad Sci USA 104: 3360-3365, 2017.

19 Aust S, Felix S, Auer K, Bachmayr-Heyda A and Kenner L, Dekan S, Meier SM, Gerner C, Grimm C and Pils D: Absence of PD-L1 on tumor cells is associated with reduced MHC I expression and PD-L1 expression increases in recurrent serous ovarian cancer. Sci Rep 7: 42929, 2017.

20 Darb-Esfahani S and Kunze CA, Kulbe H, Sehouli J, Wienert S, Lindner J, Budczies J, Bockmayr M, Dietel M, Denkert C, Braicu I, Jöhrens K: Prognostic impact of programmed cell death-1 (PD-1) and PD-ligand 1 (PD-L1) expression in cancer cells and tumor-infiltrating lymphocytes in ovarian high-grade serous carcinoma. Oncotarget 7: 1486-1499, 2016.

21 Webb JR, Milne K, Kroeger DR and Nelson BH: PD-L1 expression is associated with tumor-infiltrating T-cells and favorable prognosis in high-grade serous ovarian cancer. Gynecol Oncol 141: 293-302, 2016.

22 Gottlieb CE, Mills AM, Cross JV and Ring KL: Tumor-associated macrophage expression of PD-L1 in implants of high grade serous ovarian carcinoma: A comparison of matched primary and metastatic tumors. Gynecol Oncol 144: 607-612, 2017. 
23 Chatterjee J, Dai W, Aziz NHA, Teo PY, Wahba J, Phelps DL, Maine CJ, Whilding LM, Dina R, Trevisan G, Flower KJ, George AJT and Ghaem-Maghami S: Clinical use of programmed cell death-1 and its ligand expression as discriminatory and predictive markers in ovarian cancer. Clin Cancer Res 23: 3453-3460, 2017.

24 Zhou J, Mahoney KM, Giobbie-Hurder A, Zhao F, Lee S, Liao X, Rodig S, Li J, Wu X, Butterfield LH, Piesche M, Manos MP, Eastman LM, Dranoff G, Freeman GJ and Hodi FS: Soluble PDL1 as a biomarker in malignant melanoma treated with checkpoint blockade. Cancer Immunol Res 5: 480-492, 2017.

25 Frigola X, Inman BA, Lohse CM, Krco CJ, Cheville JC, Thompson RH, Leibovich B, Blute ML, Dong H and Kwon ED: Identification of a soluble form of $\mathrm{B} 7-\mathrm{H} 1$ that retains immunosuppressive activity and is associated with aggressive renal cell carcinoma. Clin Cancer Res 17: 1915-1923, 2011.

26 Rossille D, Gressier M, Damotte D, Maucort-Boulch D and Pangault C, Semana G, Le Gouill S, Haioun C, Tarte K and Lamy T: High level of soluble programmed cell death ligand 1 in blood impacts overall survival in aggressive diffuse large BCell lymphoma: Results from a French multicenter clinical trial. Leukemia 28: 2367-2375, 2014

27 Garcia-Diaz A and Shin DS, Moreno BH, Saco J, EscuinOrdinas H and Rodriguez GA, Zaretsky JM, Sun L, Hugo W, Wang X, Parisi G, Saus CP, Torrejon DY, Graeber TG, CominAnduix B, Hu-Lieskovan S and Damoiseaux R, Lo RS and Ribas A: Interferon receptor signaling pathways regulating PDL1 and PD-L2 expression. Cell Rep 19: 1189-1201, 2017.

28 Chen N, Fang W, Lin Z, Peng P, Wang J, Zhan J, Hong S, Huang $\mathrm{J}$, Liu L, Sheng J, Zhou T, Chen Y, Zhang $\mathrm{H}$ and Zhang L: KRAS mutation-induced up-regulation of PD-L1 mediates immune escape in human lung adenocarcinoma. Cancer Immunol Immunother 66: 1175-1187, 2017.

29 Okita R, Maeda A, Shimizu K, Nojima Y, Saisho S and Nakata M: PD-L1 overexpression is partially regulated by EGFR/HER2 signaling and associated with poor prognosis in patients with non-small-cell lung cancer. Cancer Immunol Immunother 66: 865-876, 2017.

30 Yang M, Liu P, Wang K, Glorieux C, Hu Y, Wen S, Jiang W and Huang P: Chemotherapy induces tumor immune evasion by upregulation of programmed cell death ligand 1 expression in bone marrow stromal cells. Mol Oncol 11: 358-372, 2017.
31 Fujita Y, Yagishita S, Hagiwara K, Yoshioka Y, Kosaka N, Takeshita F, Fujiwara T, Tsuta K, Nokihara H, Tamura T, Asamura H, Kawaishi M, Kuwano K and Ochiya T: The clinical relevance of the $m i R-197 / \mathrm{CKS} 1 \mathrm{~B} / \mathrm{STAT} 3$-mediated PD-L1 network in chemoresistant non-small-cell lung cancer. Mol Ther 23: 717-727, 2015.

32 Liu XF, Wang RQ, Hu B, Luo MC, Zeng QM, Zhou H, Huang $\mathrm{K}$, Dong $\mathrm{XH}$, Luo $\mathrm{YB}$, Luo $\mathrm{ZH}$ and Yang $\mathrm{H}$ : MiR-15a contributes abnormal immune response in myasthenia gravis by targeting CXCL10. Clin Immunol 164: 106-113, 2016.

33 Cortez MA, Ivan C, Valdecanas D, Wang X, Wang X, Peltier HJ, Ye Y, Araujo L, Carbone DP, Shilo K, Giri DK, Kelnar K, Martin D, Komaki R, Gomez DR, Krishnan S, Calin GA, Bader AG and Welsh JW: PDL1 regulation by p53 via miR-34. J Natl Cancer Inst 108: djv303, 2015.

34 Wang X, Li J, Dong K, Lin F, Lin F, Long M, Ouyang Y, Wei J, Chen X, Weng Y, He T and Zhang $\mathrm{H}$ : Tumor suppressor $m i R$ $34 a$ targets PD-L1 and functions as a potential immunotherapeutic target in acute myeloid leukemia. Cell Signal 27: 443-452, 2015.

35 Noman MZ, Janji B, Abdou A, Hasmim M, Terry S, Tan TZ, Mami-Chouaib F, Thiery JP and Chouaib S: The immune checkpoint ligand PD-L1 is upregulated in EMT-activated human breast cancer cells by a mechanism involving ZEB-1 and miR-200. Oncoimmunology 6: e1263412, 2017.

36 Chen L, Gibbons DL, Goswami S, Cortez MA, Ahn YH, Byers LA, Zhang X, Yi X, Dwyer D, Lin W, Diao L, Wang J, Roybal JD, Patel M, Ungewiss C, Peng D, Antonia S, Mediavilla-Varela M, Robertson G, Jones S, Suraokar M, Welsh JW, Erez B, Wistuba II, Chen L, Peng D, Wang S, Ullrich SE, Heymach JV, Kurie JM and Qin FX: Metastasis is regulated via microRNA200/ZEB1 axis control of tumour cell PD-L1 expression and intratumoral immunosuppression. Nat Commun 5: 5241, 2014.

Received August 29, 2018

Revised September 6, 2018

Accepted September 17, 2018 